\title{
Bioactivity of Spagneticola trilobata Flower Extract against Fall Army Worm Spodoptera frugiperda J. E. Smith
}

\author{
R. Arif Malik Ramadhan ${ }^{1} *$ dan Efrin Firmansyah ${ }^{1}$ \\ ${ }^{1}$ Agrotechnology Study Program, Agriculture Faculty, Universitas Perjuangan Tasikmalaya, West Java, Indonesia, 46115. \\ *Corresponding Author: am.ramadhan@unper.ac.id
}

Received July 23, 2020; revised September 17, 2020; accepted December 11, 2020

\begin{abstract}
Fall armyworm (Spodoptera frugiperda) is a new pest that attacks maize plantations in Indonesia. Local farmers generally use synthetic pesticides to control the pest that can cause environmental and health problems, and in the future will trigger resistance of the pest to insecticide. This study aimed to determine the potential of Sphagneticola trilobata flower extracts on mortality, larval weight, weight of food consumption, and inhibition of feeding activity in $S$. frugiperda larvae. The research method is completely randomized design with 6 treatments and 3 replications. The treatments consisted of control treatments, S. trilobata flower extract 1\%, 2\%, 3\%, 4\%, and 5\%. Mortality, larval weights and food consumption data were analyzed using analysis of variance. The results showed that the S. trilobata flower extract at the highest concentration of 5\% resulted in larval mortality of 72.22 . These results indicated that the S. trilobata flower extract was not effective against $\mathrm{S}$. frugiperda. However, $S$. trilobata extract can influence other biological aspects, such as feeding activity and growth of $S$. frugiperda larvae. Tratment of 5\% of S. trilobata extract resulted in weight of feed comsumption of $0.123 \mathrm{~g}$ with inhibition of feeding activity of $66.11 \%$, and average weight of larvae of $0.048 \mathrm{~g}$ that were lower than control treatment.
\end{abstract}

Keywords: Spodoptera frugiperda, Sphagneticola trilobata, Botanical Pesticides

\section{ABSTRAK}

Bioaktivitas Ekstrak Bunga Sphagneticola trilobata terhadap Ulat Grayak Jagung Spodoptera frugiperda J. E. Smith

Ulat grayak jagung (Spodoptera frugiperda) merupakan hama baru yang menyerang pertanaman jagung di Indonesia. Pengendalian hama tanaman oleh petani umumnya masih menggunakan insektisida sintetik yang dapat menimbulkan permasalahan lingkungan dan kesehatan, serta dapat memicu terjadinya resistensi serangga hama. Penelitian ini bertujuan untuk mengetahui potensi ekstrak bunga Sphagneticola trilobata terhadap mortalitas, bobot larva, dan penghambatan aktivitas makan larva S. frugiperda. Metode penelitian menggunakan rancangan acak lengkap dengan 6 perlakuan dan 3 ulangan. Perlakuan terdiri atas perlakuan kontrol, ekstrak bunga S. trilobata 1\%, 2\%, 3\%, 4\%, dan 5\%. Data mortalitas, bobot larva dan penghambatan aktivitas makan dianalisis menggunakan sidik ragam. Hasil penelitian menunjukkan bahwa ekstrak bunga $S$. trilobata pada konsentrasi tertinggi 5\% mengakibatkan mortalitas larva sebesar 72,22. Hasil ini menunjukkan bahwa ekstrak bunga $S$. trilobata tidak efektif terhadap $S$. frugiperda. Namun, ekstrak S. trilobata dapat mempengaruhi aspek biologi lainnya yaitu aktivitas makan dan pertumbuhan larva $S$. frugiperda. Perlakuan ekstrak $S$. trilobata menghasilkan konsumsi pakan sebesar $0.123 \mathrm{~g}$ dengan penghambatan aktivitas makan sebesar $66,11 \%$ dan bobot rata-rata larva sebesar $0,048 \mathrm{~g}$ yang lebih rendah dibandingkan perlakuan kontrol.

Kata Kunci: Spodoptera frugiperda, Sphagneticola trilobata, Pestisida Nabati

\section{PENDAHULUAN}

Ulat grayak jagung (Spodoptera frugiperda) merupakan hama penting pada komoditas serealia yang dilaporkan dapat menyerang lebih dari 100 spesies tanaman dengan inang utama berupa tanaman jagung (FAO \& CABI 2019). Serangan $S$. frugiperda dapat menyebabkan kehilangan hasil sebesar 20-50\% pada jagung dan pada jagung manis sebesar $80-90 \%$ (Early et al., 2018; FAO, 2019). Serangan S. frugiperda dapat berakibat buruk pada tanaman jagung karena hama tersebut dapat merusak seluruh bagian tanaman jagung (Nonci et al., 2019). Pada bulan Maret 2019 dilaporkan peristiwa serangan $S$. frugiperda pertama di Indonesia, yakni di daerah Pasaman Sumatera Barat (Nonci et al., 2019) disusul dengan laporan serangan S. frugiperda di Jawa Barat seperti Bandung, Garut, Sumedang, pada Juni 2019 (Maharani et al., 2019).

Pengendalian hama di Indonesia pada umumnya menggunakan pestisida sintetik yang memiliki berbagai dampak negatif seperti permasalahan kesehatan, permasalahan lingkungan, serta meningkatkan peluang terjadinya resistensi pada S. frugiperda. Pemerintah telah mengatur cara penanggulangan hama melalui UU nomor 22 tahun 2019 yang mengatur bahwa pengendalian hama menggunakan sistem pengelolaan hama terpadu dalam upaya menciptakan sistem pertanian berkelanjutan. Penggunaan insektisida nabati merupakan salah satu komponen pengelolaan hama terpadu yang relatif lebih aman dibandingkan pengendalian dengan insektisida sintetik. 
Kelimpahan dan ketersediaan tumbuhan di Indonesia memberikan peluang tinggi bagi para peneliti untuk mengeksplorasi berbagai tumbuhan berpotensi sebagai bahan baku insektisida nabati. Tumbuhan Spagneticola trilobata (Asteraceae: Asterales) merupakan tumbuhan gulma yang keberadaannya melimpah serta pemanfaatannya di Indonesia dinilai relatif rendah. Tumbuhan $S$. trilobata telah diteliti dan dilaporkan memiliki kandungan senyawa $\alpha$-pinene, limonene, $\alpha$ phellandrene and $\beta$ phellandren yang dapat digunakan untuk mengendalikan serangga (Khater \& El-Shafiey 2015). Junhirun et al. (2012) melaporkan bahwa ekstrak $S$. trilobata yang diaplikasikan secara topikal efektif mengendalikan larva Plutella xylostella (Lepidoptera:Plutellidae).

Ekstrak S. trilobata juga dilaporkan dapat mengedalikan larva Spodoptera litura (Lepidoptera:Noctuidae) instar ke-2 pada skala laboratorium (Firmansyah \& Pusparani 2019; Yooboon et al. 2019). Berdasarkan hasil studi literatur keefektifan $S$. trilobata terhadap berbagai serangga hama dari ordo lepidoptera, dirasa perlu menggali potensi tumbuhan tersebut lebih lanjut. Penelitian ini bertujuan untuk mengetahui pengaruh pemberian ekstrak bunga $S$. trilobata terhadap mortalitas, pertumbuhan, konsumsi pakan, dan penghambatan aktivitas makan pada larva $S$. frugiperda.

\section{BAHAN DAN METODE}

\section{a. Persiapan Serangga Uji}

Serangga uji yang digunakan dalam penelitian ini merupakan larva $S$. frugiperda instar dua yang diperoleh dari Laboratorium Pestisida dan Toksikologi Lingkungan, Departemen Hama dan Penyakit Tumbuhan, Fakultas Pertanian, Universitas Padjadjaran. Pemeliharaan dan perbanyakan serangga uji dilaksanakan di Laboratorium Fakultas Pertanian, Universitas Perjuangan Tasikmalaya. Larva $S$. frugiperda dipelihara di dalam kotak pemeliharaan berukuran 40 × 20 × $10 \mathrm{~cm}$ hingga larva membentuk pupa. Pakan yang diberikan selama proses pemeliharaan larva berupa jagung semi. Bagian bawah kotak pemeliharaan diberi serbuk gergaji untuk menjaga kelembaban kotak pemeliharaan akibat kotoran S. frugiperda. Kepadatan populasi dalam kotak pemeliharaan dijaga untuk memperkecil kemungkinan terjadinya kanibalisme larva $S$. frugiperda.

Larva dipelihara hingga membentuk pupa di dalam kotak pemeliharaan tersebut. Setelah $S$. frugiperda membentuk pupa kemudian dipindahkan ke dalam kotak pemeliharaan dengan ukuran yang lebih besar. Tujuannya agar pemberian pakan dan pemanenan telur dari imago $S$. frugiperda dapat dilaksanakan dengan lebih praktis. Pakan imago $S$. frugiperda merupakan madu yang dilarutkan dalam air dengan konsentrasi $10 \%$. Pemberian pakan dilakukan dengan cara menggantung kapas yang telah diberi larutan madu $10 \%$. Pemberian pakan dilakukan pada pagi dan malam hari hingga imago mati. Pemanenan telur dilakukan dengan interval 1 x 24 jam dengan menggunakan kuas halus dan cawan petri. Telur yang telah dipanen kemudian dikelompokkan berdasarkan waktu pemanenan terlur. Proses tersebut terus diulang hingga populasi serangga uji memenuhi jumlah kebutuhan untuk pengujian.

\section{b. Ekstraksi Bunga S. trilobata}

Insektisida nabati yang digunakan dalam penelitian ini merupakan ekstrak bunga S. trilobata yang diperoleh dari Kecamatan Tawang, Kota Tasikmalaya. Tahapan ekstraksi dilakukan merujuk pada metode maserasi yang dilakukan oleh Dadang \& Prijono (2008). Tahapan awal dalam proses ekstraksi ini dilakukan dengan memotong-motong bagian bunga $S$. trilobata kemudian dikering anginkan. Bunga $S$. trilobata yang telah kering kemudian dihaluskan dengan menggunakan alat penggiling hingga menjadi serbuk.

Serbuk tersebut kemudian disaring dengan saringan $1 \mathrm{~mm}$ kemudian direndam dalam larutan metanol selama 48 jam. Proses perendaman terus diulang hingga larutan tidak berubah warna. Larutan hasil rendaman kemudian disaring menggunakan kertas saring Whatman no. 41. Hasil penyaringan diuapkan dengan menggunakan alat rotary evaporator pada suhu $50^{\circ} \mathrm{C}$ dan tekanan 240 mbar hingga terbentuk ekstrak kasar bunga $S$. trilobata dalam bentuk pasta. Ekstrak kemudian disimpan dalam lemari es dengan suhu $4^{\circ} \mathrm{C}$ hingga saat digunakan.

\section{c. Pengujian}

Pengujian dilaksanakan menggunakan rancangan acak lengkap dengan menggunakan 5 taraf konsentrasi yaitu kontrol, 1\%, 2\%, 3\%, 4\%, dan 5\% sebagai perlakuan yang kemudian diulang sebanyak tiga kali pengulangan. Pada konsentrasi $1 \%$ digunakan $1 \mathrm{ml}$ larutan ekstrak bunga $S$. trilobata $(1 \mathrm{~g}$ ekstrak : $1 \mathrm{ml}$ metanol) yang ditambahkan $99 \mathrm{ml}$ aquadest steril. Pada konsentrasi 2\% digunakan $2 \mathrm{ml}$ larutan ekstrak bunga $S$. trilobata yang ditambahkan $98 \mathrm{ml}$ aquadest steril, dan seterusnya pada perlakuan $3 \%$, 4\%, dan 5\%. Pengaplikasian ekstrak bunga $S$. trilobata dilakukan dengan cara mencelupkan pakan berupa jagung semi ke dalam larutan dengan konsentrasi sesuai perlakuan selama 30 detik. Pakan yang telah diberi perlakuan kemudian dikering anginkan, ditimbang, dan diberikan kepada serangga uji.

Pada setiap perlakuan digunakan 10 ekor larva $S$. frugiperda instar dua. Setiap larva ditempatkan dalam satu buah tabung pengujian berdiameter $2,5 \mathrm{~cm}$ dan tinggi $5 \mathrm{~cm}$. Pengujian dilakukan secara terpisah bertujuan untuk mencegah data yang tidak akurat akibat sifat kanibalisme yang dimiliki larva $S$. frugiperda. Pakan dipotong sepanjang $\pm 2 \mathrm{~cm}$ agar dapat masuk ke dalam tabung 
pengujian. Pemberian pakan berperlakuan dilakukan selama 48 jam. Setelah pemberian pakan selama 48 jam pakan ditimbang kemudian diganti menggunakan jagung semi tanpa perlakuan dan pengamatan terus dilakukan hingga larva mencapai instar ke-4.

\section{d. Pengamatan dan analisis data}

Parameter yang diamati dalam penelitian ini adalah mortalitas larva, bobot larva, bobot konsumsi pakan, dan efek penghambatan makan (antifeedant). Pengamatan mortalitas larva dihitung secara kumulatif hingga larva mencapai instar ke-4. Data mortalitas dianalisis dengan sidik ragam dan uji jarak berganda duncan menggunakan perangkat lunak SPSS versi 25. Data disajikan dalam nilai rata-rata dan simpangan baku. Pengamatan bobot larva dihitung pada saat larva mencapai instar empat. Pengukuran bobot larva digabungkan dalam setiap ulangan kemudian hasilnya ditimbang dan dihitung bobot rata-ratanya. Pegamatan bobot konsumsi pakan dilakukan pada 48 jam setelah perlakuan. Penghitungan bobot konsumsi pakan dilakukan dengan cara menimbang bobot pakan sebelum dan setelah 48 jam perlakuan. Bobot konsumsi pakan dihitung berdasarkan bobot pakan sebelum perlakuan dikurangi bobot pakan setelah diberikan kepada serangga uji selama 48 jam. Bobot konsumsi pakan yang diamati merupakan bobot basah pakan. Data bobot konsumsi pakan dianalisis menggunakan analisis sidik ragam, kemudian signifikansi antar perlakuan diuji dengan analisis jarak berganda Duncan pada taraf kepercayaan 5\%. Pengukuran penghambatan aktivitas makan dihitung berdasarkan bobot konsumsi pakan dengan menggunakan rumus (Junhirun et al., 2018).

$$
A=\frac{(K-P)}{K} \times 100
$$

Keterangan:

$$
\begin{array}{ll}
\mathrm{A} & \text { : Efek penghambatan makan }(\%) \\
\mathrm{K} & \text { : Konsumsi pakan kontrol }(\mathrm{g}) \\
\mathrm{P} & \text { : Konsumsi pakan berperlakuan }(\mathrm{g})
\end{array}
$$

\section{HASIL DAN PEMBAHASAN}

Hasil percobaan menunjukkan bahwa perlakuan ektrak bunga S.trilobata pada konsentrasi tertinggi 5\% hanya mengakibatkan kematian serangga uji sebesar 72,22\%, sedangkan respons mortalitas paling rendah ditunjukkan pada perlakuan ekstrak $S$. trilobata $1 \%$ dengan respons mortalitas sebesar $11,11 \%$ (Tabel 1). Hasil pengujian ekstrak bunga $S$. trilobata terhada $S$. frugiperda dinilai tidak efektif karena konsentrasi yang dibutuhkan untuk mematikan serangga uji terlalu tinggi atau jumlah ekstrak yang dibutuhkan untuk mengendalikan serangga hama dinilai tidak rasional. Signifikansi pada seluruh perlakuan berbeda nyata, terkecuali pada konsentrasi $1 \%$ dan $2 \%$ dengan P-value sebesar 0,838. Junhirun et al. (2018) menyatakan bahwa ekstrak metanol $S$. trilobata dapat menyebabkan mortalitas pada larva Spodoptera litura dengan nilai $\mathrm{LD}_{50}$ sebesar 35,94 $\mu \mathrm{g} /$ larva dan $10,88 \mu \mathrm{g} /$ larva pada $S$. exigua. Firmansyah \& Pusparani (2019) melaporkan bahwa ekstrak daun S. trilobata $5 \%$ dapat menyebabkan mortalitas S. litura sebesar $72 \%$. Berdasarkan laporan tersebut $S$. litura dan $S$. frugiperda memilki tingkat kepekaan yang serupa terhadap ekstrak $S$. trilobata.

Tabel 1. Pengaruh pemberian ekstrak S. trilobata terhadap mortalitas kumulatif $S$. frugiperda 12 hari setelah aplikasi.

\begin{tabular}{ccc}
\hline Perlakuan & Mortalitas (\%) & $\mathrm{n}$ \\
\cline { 2 - 3 } Ekstrak S. Trilobata & $\bar{X} \pm \mathrm{SD}$ & 30 \\
\hline Kontrol & $0 \pm 0 \mathrm{a}$ & 30 \\
$1 \%$ & $11,11 \pm 1,92 \mathrm{~b}$ & 30 \\
$2 \%$ & $13,33 \pm 3,33 \mathrm{~b}$ & 30 \\
$3 \%$ & $35,56 \pm 3,85 \mathrm{c}$ & 30 \\
$4 \%$ & $57,78 \pm 3,85 \mathrm{~d}$ & 30 \\
\hline
\end{tabular}

Keterangan: $\bar{X}$ : rata-rata mortalitas larva SD: Standar Deviasi n: Jumlah serangga uji Angka yang diikuti dengan huruf yang berbeda menunjukkan perbedaan yang signifikan menurut uji jarak berganda Duncan pada taraf kepercayaan 5\%.

Larva $S$. frugiperda yang telah mengonsumsi pakan berperlakuan umumnya tidak menunjukkan gejala keracunan pada 1 HSA (hari setelah aplikasi). Respons mortalitas mulai ditunjukkan pada 2 dan 3 HSA. Larva $S$. frugiperda yang mengonsumsi ekstrak S. trilobata dalam jumlah yang mematikan akan mengalami kematian dalam waktu 2-3 HSA (Gambar 1). Larva yang mati menunjukkan gejala berkerut dengan tubuh berwarna kehitaman. Larva yang mengonsumsi ekstrak $S$. trilobata dalam jumlah yang tidak mematikan akan mengalami penurunan tingkat konsumsi pakan sehingga larva yang bertahan hidup akan mengalami berbagai gangguan pertumbuhan. Sebagian larva $S$. frugiperda yang pertumbuhannya terganggu dapat pulih dari kondisi tersebut kemudian bertahan hidup selayakya larva normal, sebagian larva mengalami kematian akibat gangguan pertumbuhan tersebut. 


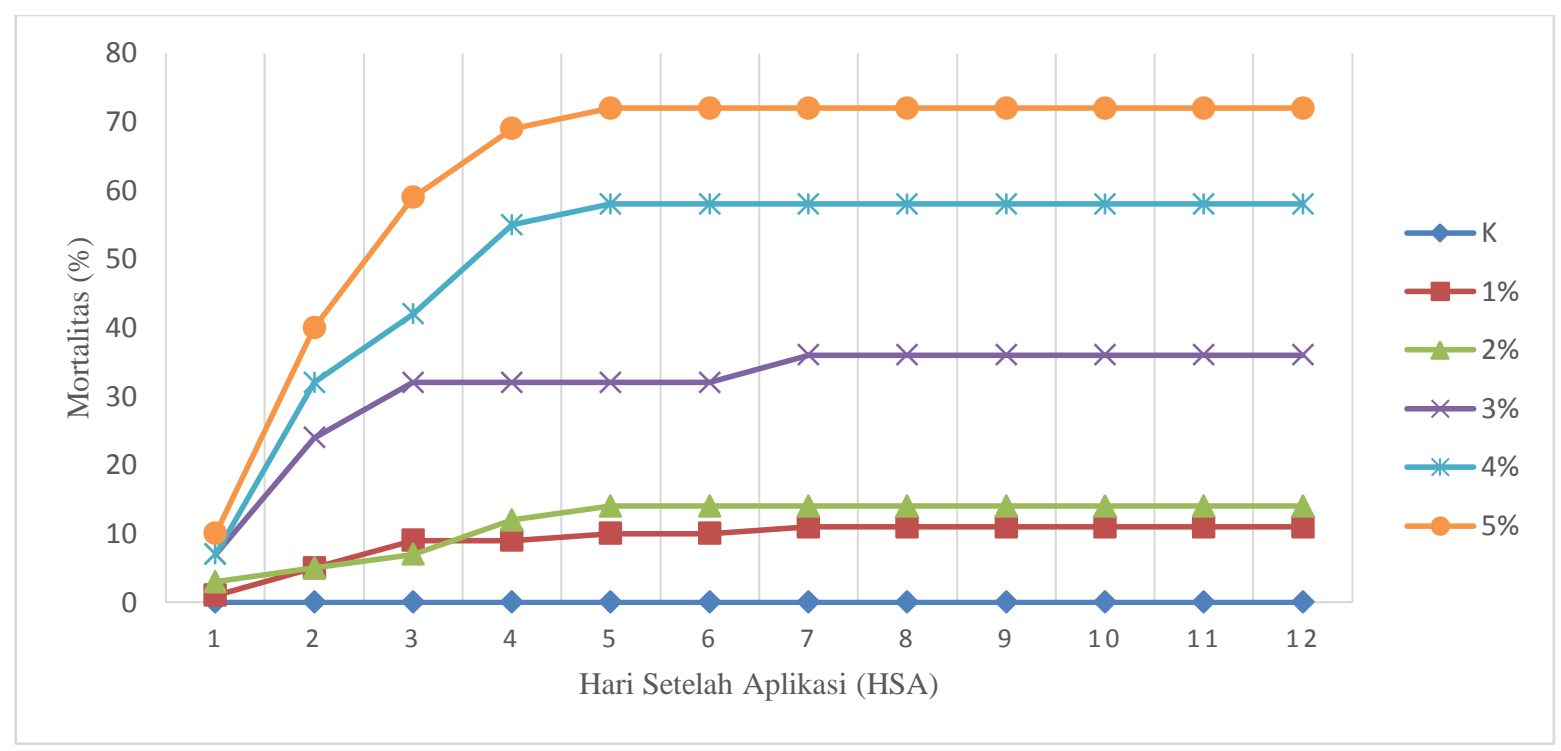

Gambar 1. Mortalitas kumulatif larva S. frugiperda pada 12 HAS

Pakan berperlakuan ekstrak $S$. trilobata menimbulkan efek penghambatan aktivitas makan serangga uji. Pada perlakuan dengan konsentrasi $1 \%$ dan 2\% sebagian besar larva tidak menunjukkan perilaku penolakkan terhadap pakan yang diberikan. Pada perlakuan dengan konsentrasi 3\%, 4\%, dan 5\% sebagian larva memperlihatkan perilaku menjauh dari pakan berperlakuan dan tidak mengkonsumsi pakan berberlakuan yang diberikan. Konsumsi pakan tertinggi ditunjukkan oleh perlakuan kontrol dengan bobot konsumsi pakan sebesar 0,363 $\pm 0,022 \mathrm{~g}$ dan paling rendah ditunjukkan oleh perlakuan ekstrak $S$. trilobata 5\% dengan bobot konsumsi pakan sebesar $0,123 \pm 0,009 \mathrm{~g}$ (Tabel 2).

Pengaruh perlakuan ekstrak terhadap bobot larva uji menunjukkan bahwa rata-rata bobot larva paling tinggi ditunjukkan oleh perlakuan kontrol yaitu sebesar 0,285 gram per larva sementara rata-rata bobot larva paling rendah terdapat pada perlakuan ekstrak $S$. trilobata 5\% yaitu sebesar $0,048 \pm 0,011 \mathrm{~g}$ (Tabel 3). Aktivitas penghambat makan dari ekstrak akan mempengaruhi jumlah pakan yang dikonsumsi oleh serangga uji dan pada akhirnya berdampak pada bobot larva (Ramadhan et al., 2016). Efek penghambatan makan dapat menurunkan tingkat konsumsi pakan dari larva $S$. frugiperda yang diujikan. Penurunan tingkat konsumsi pakan tersebut mengakibatkan larva $S$. frugiperda mengalami kekurangan nutrisi yang dibutuhkan untuk menunjang pertumbuhan larva sehingga bobot larva relatif lebih rendah dari perlakuan kontrol.

Tabel 2. Pengaruh konsentrasi ekstrak S. trilobata terhadap bobot konsumsi pakan dan penghambatan makan larva $S$. frugiperda

\begin{tabular}{ccc}
\hline Perlakuan & Bobot Konsumsi Pakan (g) & Penghambatan Makan (\%) \\
\hline Kontrol & $0,363 \pm 0,022 \mathrm{a}$ & $0 \mathrm{a}$ \\
$1 \%$ & $0,293 \pm 0,025 \mathrm{~b}$ & $19,29 \mathrm{~b}$ \\
$2 \%$ & $0,282 \pm 0,022 \mathrm{~b}$ & $22,31 \mathrm{~b}$ \\
$3 \%$ & $0,215 \pm 0,011 \mathrm{c}$ & $40,77 \mathrm{c}$ \\
$4 \%$ & $0,157 \pm 0,023 \mathrm{~d}$ & $56,75 \mathrm{~d}$ \\
$5 \%$ & $0,123 \pm 0,009 \mathrm{e}$ & $66,11 \mathrm{e}$ \\
\hline
\end{tabular}

Keterangan: Angka yang diikuti dengan huruf yang berbeda menunjukkan perbedaan yang signifikan menurut uji jarak berganda Duncan pada taraf kepercayaan 5\%.

Tabel 3. Pengaruh konsentrasi S. trilobata terhadap bobot larva $S$. frugiperda instar ke-4.

\begin{tabular}{ccc}
$\begin{array}{c}\text { Perlakuan } \\
\text { trak S. trilobata }\end{array}$ & Bobot Larva $(\mathrm{g})$ & $\begin{array}{c}\text { Jumlah Serangga } \\
\text { Uji (Ekor) }\end{array}$ \\
\hline Kontrol & $0,285 \pm 0,030$ & 30 \\
$1 \%$ & $0,198 \pm 0,012$ & 27 \\
$2 \%$ & $0,191 \pm 0,024$ & 26 \\
$3 \%$ & $0,125 \pm 0,015$ & 19 \\
$4 \%$ & $0,083 \pm 0,018$ & 13 \\
$5 \%$ & $0,048 \pm 0,011$ & 8 \\
\hline
\end{tabular}




\section{KESIMPULAN DAN SARAN}

Ekstrak metanol bunga $S$. trilobata yang diujikan dinilai tidak efektif untuk mengendalikan $S$. frugiperda. Ekstrak S. trilobata pada konsentrasi 5\% hanya dapat menyebabkan mortalitas sebesar $72,22 \%$. Namun, ekstrak $S$. trilobata dapat mempengaruhi aspek biologi lainnya yaitu penghambatan pertumbuhan dan konsumsi pakan pada larva $S$. frugiperda. Ekstrak S. trilobata konsentrasi 5\% mengakibatkan penghambatan aktivitas makan pada larva $S$. frugiperda sebesar $66,11 \%$ dibandingkan dengan perlakuan kontrol. Penghambatan aktivitas makan tersebut dapat mempengaruhi pertumbuhan larva S. frugiperda. Pada perlakuan kontrol, bobot larva $S$. frugiperda instar ke-4 sebesar 0,285 $\pm 0,030$, sementara pada perlakuan ekstrak S. trilobata 5\% bobot larva yang sebesar $0,048 \pm 0,011 \mathrm{~g}$.

\section{UCAPAN TERIMA KASIH}

Ucapan terima kasih disampaikan kepada Laboratorium Pestisida dan Toksilogi Lingkungan, Departemen Hama dan Penyakit Tumbuhan, Fakultas Pertanian, Universitas Padjadjaran yang telah membantu menyediakan serangga uji untuk kepentingan penelitian ini.

\section{DAFTAR PUSTAKA}

Early R, González-Moreno P, Murphy ST, \& Day R. 2018. Forecasting the global extent of invasion of the cereal pest Spodoptera frugiperda, the fall armyworm. NeoBiota, 50(40): 25-50.

FAO. 2019. Briefing Note on FAO Actions on Fall Armyworm in Africa. FAO Briefing Note on FAW, 1(March), 1-7.

FAO, \& CABI. 2019. Community-Based Fall Armyworm (Spodoptera frugiperda) Monitoring, Early Warning and Management.

Firmansyah E, \& Pusparani S. 2019. The potential leaf extract of Sphagneticola trilobata as botanical insecticide to control Spodoptera litura larvae. Musamus J. Agrotech. Research (MJAR), II(I): 13-19.

Junhirun P, Pluempanupat W, Yooboon T, Ruttanaphan T, Koul O, \& Bullangpoti V. 2018. The study of isolated alkane compounds and crude Extracts from Sphagneticola trilobata (Asterales: Asteraceae) as a candidate botanical insecticide for lepidopteran larvae. J. Econ. Entomol. 111(6): 2699-2705.

Khater KS, \& El-Shafiey SN. 2015. Insecticidal effect of essential oils from two aromatic plants against Tribolium castaneum (Herbst), (Coleoptera: Tenebrionidae). Egypt. J. Biol. Pest Control. 25(1): 129-134.

Maharani Y, Dewi VK, Puspasari LT, Rizkie L, Hidayat Y, \& Dono D. 2019. Cases of fall army worm Spodoptera frugiperda J. E. Smith (Lepidoptera: Noctuidae) attack on maize in Bandung, Garut and Sumedang district, West Java. Cropsaver. 2(1): 38-46.

Nonci N, Kalqutny SH, Mirsam H, Muis A, Azrai M, \& Aqil M. 2019. Pengenalan Fall Armyworm (Spodoptera frugiperda J. E. Smith) Hama Baru Pada Tanaman Jagung di Indonesia. Kementrian Pertanian Badan Penelitian dan Pengembangan Pertanian Balai Penelitian Tanaman Serealia.

Ramadhan RAM, Puspasari LT, Meliansyah R, Maharani R, Hidayat Y, \& Dono D. 2016. Bioaktivitas formulasi minyak biji Azadirachta indica (A. Juss) terhadap Spodoptera litura F. Agrikultura. 27(1): 1-8.

Yooboon T, Pengsook A, Ratwatthananon A, Pluempanupat W, \& Bullangpoti V. 2019. A plant-based extract mixture for controlling Spodoptera litura (Lepidoptera: Noctuidae). Chem. and Biol. Tech. in Agric. 6(1), 1-10.

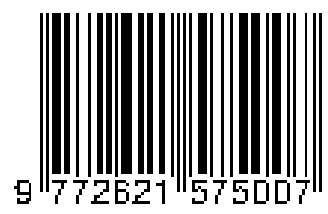

